\title{
Discussion on the Role of Heilongiiang Tourism Crafts in Promoting the Development of Tourism Culture and Creative Industries*
}

\author{
Hui Xie \\ Heihe University \\ Heihe, China 164300
}

\author{
Yan Zhang \\ Heihe University \\ Heihe, China 164300
}

\begin{abstract}
Located in the northern China, Heilongjiang is cold in autumn and winter and the temperature difference there changes greatly. Therefore, a unique social and meteorological landscape is formed. In terms of geographical location, Heilongjiang Province is adjacent to Russia, so there are exchanges in culture and economy, which also makes the local tourism crafts have more unique manufacturing processes with more foreign characteristics. The promotion of tourism crafts in Heilongjiang has also become an important part of the local tourism bureau in promoting the development of local tourism.
\end{abstract}

Keywords-tourism; tourism crafts; culture and creative industries

\section{INTRODUCTION}

In today's society where social economy and science and technology are developing rapidly, the tourism cultural creative industry will become one of the most promising industries. In recent years, it has developed rapidly in major cities. People are no longer just like in previous times when they are only confined to solving the problem of food and clothing, and they dare not wish to travel. Now people's income has increased year by year, and their living standards have been continuously improved. Everyone has gone out of their homes and even went abroad to travel and appreciate the great rivers and mountains and cultural industries in China. Nowadays, the development of tourism crafts has made great contributions to the development of China's tourism culture and creative industries, and to a certain extent has become a pillar of the development of tourism culture and creative industries.

\section{DEVELOPMENT OF TOURISM CULTURE AND CREATIVE INDUSTRIES}

Culture and creative industries is recognized as one of the most promising cultural industries in the 21 st century, and tourism plays an important role in its development process, which has greatly promoted the development of cultural and creative industries. The culture and creative industry is an

*Project Source: 2018 Heilongjiang Philosophy and Social Science Planning Project "Research on the Development Path of Tourism Artwork Industrialization in Heilongjiang Province" (Project No. 18YSE617). emerging industry created in the context of economic globalization, which integrates culture, creativity and tourism On the basis of full respect for intellectual property, combined with the creativity of creators, it integrates with modern high technology, combines wisdom and art, and makes promotion and improvement to produce products with higher value, which creates fortune and carries forward the culture. In other words, the originality and variability of tourism culture are integrated to develop, and the valueadded function of the industry will be given play to promote the development of the tourism economy. This is a brandnew economic industry model with high added value, strong knowledge, high degree of integration, and more content.

\section{THE RELATIONSHIP BETWEEN TOURISM CRAFTS AND TOURISM CULTURE AND CREATIVE INDUSTRIES}

\section{A. Travel Crafts}

Due to the differences in geographical conditions and natural environment, different regions have produced distinct and unique cultural characteristics through long-term historical and cultural changes. This culture is the precipitation and redefinition of the national way of thinking in the region, which is an integrated culture. There are 56 ethnic groups in China, each of which has its own unique culture. Tourism handicrafts are products that combine local cultural characteristics in the tourism process. They are commemorative and satisfy the needs of consumers in the consumer market, symbolizing the local tourism culture and greatly promoting the local economic development. Tourism crafts are the carrier of tourism culture to show the local excellent culture, which occupies a considerable proportion of tourism expenditures. For consumers, it not only has a commemorative significance but also a certain collection value. Tourism crafts are beautiful artworks that is carefully and reasonably designed and made of local unique materials, which have high artistic value. Tourism crafts have strong market development potential, and there is also huge market competitiveness. Heilongjiang Province is a province with abundant tourism resources and a long history and culture, so it has great potential for developing tourism. Since ancient times, Heilongjiang Province has been a place where ethnic minorities, such as Han, Manchu, North Korean, and Hui, 
live together, so it has a broader space to develop tourist crafts with ethnic characteristics to make tourists feel the cultural characteristics of Heilongjiang. For example, Yichun, known as the "forest capital of China", is rich in forest resources. We can open the market for tourist crafts by producing wood carvings. Wood carving is a unique handicraft made from local materials under the unique natural conditions. It has low production cost and high development and application value. We can sculpt according to the different forms of the roots and give them artistry to make potted carvings and put them in the market, in order to increase the tourism income of Yichun. In Yichun, it is possible to engrave pecans and hazelnuts into some pendants, which can be used as decorations, such as keychains and mobile phone chains, and it is also possible to make peach wood into a wooden sword as a gift for children, which has obvious local features. Therefore, we must develop more tourism crafts to attract many tourists from home and abroad to travel in Heilongjiang, and promote the tourism and economic development of Heilongjiang.

\section{B. The Relationship Between Tourism Crafts and Tourism Culture and Creative Industries}

With the rapid development of tourism in recent years, tourism crafts and tourism culture have merged together and become an irreversible trend. In people's production and life, people's needs will be transformed into the demand for culture. Different cultures are unique lifestyles of different races, which embody the cultural customs and beliefs of the people. The emergence and development of culture is closely related to people's great wisdom and creation. People have connected culture and tourism products, which creates excellent opportunities of employment and entrepreneurship for local people, generates high economic benefits, and promotes economic development, to carries forward and inherits the fine traditional culture of the Chinese nation.

From the perspective of human economics, economic activities are inseparable from the development of culture. When people go out to travel, they will pay more attention to handicrafts with local cultural characteristics. Tourism craft is artwork with a strong cultural flavor rather than a simple commodity, which provides a new way for the development of tourism culture and creative industries. The element of the development of economic activities is the combination of region and culture. In the process of development, it is necessary to continuously explore the connotation and provide a new way for the development of economic and cultural industries. Tourism crafts are closely related to the tourism and cultural creative industries. The emergence and development of tourism culture and creative industries can better promote the integration and development of tourism culture and creative industries and other industries.

The tourism crafts with regional characteristics are an important part of the tourism culture and creative industry. The wheat straw painting is the local characteristic of Heihe River in Heilongjiang Province, and it is the court crafts of Sui Dynasty that have been lost for many years in China. At the end of the 1990s, Chinese artists finally made the straw paintings reappear in people's field of vision. It is the natural landscape made of high-quality wheat straw and maintains its beauty and brightness through multiple processes, with a certain collection value, which is well-known throughout the world. It is a high-end art that can be used to decorate offices, hotels, homes, etc. and it can also be used as a gift for friends and relatives. It is a commercial art that promotes the development of the tourism culture and creative industries.

\section{The Relationship Between Tourism Culture and Creative Industries and Tourism}

Tourism culture and creative industries are closely related to tourism. Applying the creativity of tourism culture to the development and design of tourism has opened up new ideas for the development of tourism. In order to better meet the tourist needs and consumer needs of tourists, it is necessary to effectively combine culture and tourism. In modern tourism, tourists are no longer just satisfied with simple tourism, but they concern more about cultural needs. With the development of tourism, the tourism culture is constantly expanding, and the development of tourism crafts has attracted more tourists. Visitors can combine rich tourism experiences with tourism experience, put forward higher requirements for the development of cultural tourism creative industry, supervise the promotion and development of tourism, and promote the innovative development of tourism crafts. From the perspective of tourists' consumption and consumer psychology, the cultural and creative industries meet the experience and cultural needs of tourists through the development and utilization of intellectual property. Tourism industry in Tsitsihar develops rapidly and attracts a large number of tourists every year. It is an ecotourism resort, known as "the world's wetland, hometown of crane in China". Tsitsihar actively develops tourist souvenirs and enhances the image of the tourist city. Tsitsihar explores and develops the cultural tourism industry by organizing cultural fairs and cultural tourism festivals. Cultural tourism resources in Tsitsihar are abundant, but the degree of development is not enough, and further development is needed. From a cultural perspective, the development of Tsitsihar tourism crafts can promote the development of the tourism culture and creative industries to a deeper and broader space and the tourism crafts are more valuable than artworks that can only serve as decorations in the room.

\section{THE ROLE OF TOURISM CRAFTS IN TOURISM CULTURE AND CREATIVE INDUSTRIES}

Culture is an ideology, an important carrier for the inheritance of human civilization from ancient to modern times, a valuable asset left by our ancestors in the course of historical development, as well as the core soul of the survival and development of the nation. The tourism culture and creative industry has expanded the development space of tourism handicrafts and promoted the development of some industries. Under the perspective of regional cultural characteristics, research and development of tourism handicrafts has played a certain role in promoting the development of tourism culture and creative industries. 


\section{A. The Development of Tourism Crafts Has Realized the Sustainable Development of Tourism Resources}

With the development and upgrading of the culture and creative industries, tourism crafts have established a brand and become a tourism economy.

The inheritance and development of tourism crafts with regional characteristics will be conducive to the development and dissemination of tourism culture and creative industries. It is the presentation of production method and lifestyle in the tourist destination as well as a liquidity publicity resource, forming a tourist business card with local characteristics, which increases city popularity and made tourism activities more commemorative. Especially at the present stage in China, the production of tourist handicrafts lacks regional characteristics and creativity, with serious homogenization. According to the needs of the tourism consumer market, we should develop tourism crafts in a targeted manner, promote the rational and orderly development of cultural resources, and realize the sustainable development of tourism resources.

\section{B. The Development of Tourism Crafts Enriches the Development System of Tourism Product}

The integration of culture and tourism will promote the structural adjustment of tourism products with regional characteristics, meet more tourism consumption needs, enrich the connotation construction of tourism crafts, and promote the upgrading of tourism culture and creative industries. The tourism culture and creative industries enriched the development system of tourism products owing to its uniqueness and the artistic connotation, making tourism crafts full of attraction and regional characteristics. Regarding the development direction of tourism crafts as a tourism consumer market, relevant experts have proposed to fully exploit this regional cultural characteristic product. For example, the mineral water of Wudalianchi in Heilongjiang Province, a famous tourist resort for rehabilitation, is rich in trace elements, macro elements and various carbonate. Due to its unique geographical location, long-term drinking can effectively improve the activity of biological enzymes in the human body, promote the recovery of diseased tissues, and improve human immunity. It is the best quality mineral water among the world's three cold mineral springs. Many tourists come here to see the Wudalianchi closely and appreciate its unique geographical features. Of course, they will also buy some mineral water to share with their families to drive the development of the local tourism economy. Under the cultural background of advancing with the times, it is necessary to research and develop tourism crafts in depth, and promote tourism crafts with local characteristics, which not only inherits the local national culture, but also meets the consumer demand and expands the consumer market and influence. This is conducive to deepening the research and innovation achievements of tourism handicrafts, further enriching and improving the development system of tourism products, and promoting the healthy and vigorous development of tourism culture and creative industries.

\section{The Development of Tourism Crafts Has Promoted the Development of Tourism Economy}

The soul of tourism is culture, and tourism culture with individualized development is the value-added link of tourism economy. The gradually rising cultural and creative industries have led the development of social economy and the trend of culture, but there is still huge room for development. The tourism handicrafts with regional characteristics of cultural and creative industries are green and environment-friendly products with low energy consumption and high efficiency. They combine regional characteristics with art design, enhance the added value of tourism and crafts in cultural and creative industries, increase the artistic and cultural flavor of handicrafts, optimize the development structure of tourism culture and creative industry, promote the development of tourism economy, increase the local tourism economic income, and promote the sustainable and healthy development of tourism culture and creative industry, thus promoting the transformation of tourism economic structure.

The recent tourist boom is a catalyst for the development of tourism crafts. For example, Harbin, the capital city of Heilongjiang, is adjacent to Russia and it is an important exhibition window for Russian tourism crafts. There are not only dazzling tinware and colorful elegant lacquerware with classic simplicity, but also Matryoshka doll and colorful crystal sets, reflecting the artistic characteristics and aesthetic concepts of the Russian people. There is also the brass dragon in Heilongjiang, which is not heard by many people. As a national first-class cultural relic, it is located in the ruins of Huining mansion in Jinshangjing, Acheng. It is a combination of a dragon's head, a unicorn back, a dog body and a lion's tail, but it is a dog-sitting type, which is different from the traditional four dragon types. Its head slightly lift up, making it quiet and powerful. The brass dragon is a decoration on the emperor's seat of the Jin Dynasty. It sits in a triangular structure and is called the symbol of Acheng as a representative of the Jinyuan culture. Tourism crafts have deeply developed the potential space of the tourism crafts market, which can create a brand-new cultural brand of tourism crafts, injecting a continuous stream of cultural souls into tourism resources, effectively combining tourism culture and art design, and giving new driving force for the development of cultural and creative industries. The effective combination of tourism crafts and tourism resources will generate a new economic growth point, to effectively support the rapid development of the local tourism economy. If properly developed, it will effectively promote the integration and development of local tourism and other industries, develop local economy, improve overall economic strength, and promote the harmony, healthy and stable social development.

\section{CONCLUSION}

In summary, tourism crafts are one of the important components of the tourism culture and creative industries. Combining with the local tourism characteristics, the fashion elements are integrated to make distinctive tourism crafts. Moreover, with the upgrading and transformation of tourism 
in recent years, the diversified development of tourism culture provides an opportunity for the development of tourism culture and creative industries. Combining cultural tourism with creative industries will add attraction of the tourism industry to attract tourists and drive the development of the tourism economy. At the same time, it is necessary to vigorously develop tourism culture and creative industries, and transform tourism resources into capital for tourism development. Research and design personnel should actively research and develop more tourism crafts, guide the development of related industries such as historical national culture, and promote the tourism culture and creative industry in Heilongjiang to develop towards a better direction.

\section{REFERENCES}

[1] Li Manchun. Strategies, policies and paths of development of culturally creative industry [J]. Journal of Shenyang University of Technology (Social Science Edition), 2016, 9(4): 289-295. (in Chinese)

[2] Luo Guanghua. The development of rural tourism industry and upgrading countermeasures - Taking Guizhou province as an example [J]. Chinese Journal of Agricultural Resources and Regional Planning, 2016, 37 (11): 231-236. (in Chinese)

[3] Yang Liu. Research on the Integrative Development Model of Rural Tourism and Cultural Creative Industry in China [J]. Agricultural Economy, 2017, 45 (4): 57-58. (in Chinese)

[4] Zou Yun. Fusion development of tourism and cultural creative industry mechanism - Taking Sichuan Chengdu as an example [J]. Reformation \& Strategy, 2017, 12 (7):126-128. (in Chinese) 